\title{
Penile Fibromatosis
}

National Cancer Institute

\section{Source}

National Cancer Institute. Penile Fibromatosis. NCI Thesaurus. Code C3316.

Fibromatosis arising from the soft tissues of the penis. It is characterized by the presence of spindle-shaped fibroblasts, and an infiltrative growth pattern. It causes the penis to bend when it becomes erect. 